\title{
Game Accessibility and Advocacy for Participation of the Japanese Disability Community
}

\author{
Muneo Kaigo *(i) and Sae Okura *(1) \\ Faculty of Humanities and Social Sciences, University of Tsukuba, Ibaraki 305-8577, Japan \\ * Correspondence: mkaigo@japan.tsukuba.ac.jp (M.K.); okura.sae.gn@u.tsukuba.ac.jp (S.O.); \\ Tel.: +81-29-853-4037 (M.K.)
}

Received: 29 December 2019; Accepted: 11 March 2020; Published: 18 March 2020

\begin{abstract}
In this paper we examine the recent situation of advocacy through game accessibility of video games for people with physical disabilities and its challenges in Japan. We conducted an email survey among the dominant gaming companies in Japan. We discovered that most gaming companies developing games for those with disabilities have actually attempted to provide some consideration to people with disabilities through setting additional special functions such as "easy mode" and "support for visual disabilities". One out of five companies could be categorized as having successfully developed games based on the concept of specialized assistive technology, and the remaining companies could be categorized as having developed games for disabilities based on the concept of barrier-reducing goods. We also found out that the major Japanese gaming corporations had a tendency not to be active in communicating with the disability communities. Our results might indicate that stronger interaction with the gaming companies is one direct way to enhance further development of games for people with disabilities. In addition to that, considering that games are a significant form of social participation for people with disabilities, more social understanding is required in the Japanese domestic context.
\end{abstract}

Keywords: video games; disabilities; Japan; accessible design; corporate social responsibility; advocacy

\section{Introduction}

Video games and online games can both be considered as significant means of social participation for people with disabilities. Therefore, video game accessibility for people with disabilities must be improved not only in terms of the gaming market, but also through the amendment of laws and legislation [1]. Although games and web services for the disability community have been developed in the past, and the promotion of broader game accessibility has also been achieved to a certain extent, the diffusion of these efforts has not been as extensive as anticipated [2].

As mentioned, the national government has not been taking the necessary steps to improve game accessibility, as opposed to accessibility to television programs, e-books, and websites, which have all experienced substantial improvement. This is probably because video and online games are often reduced to being a form of entertainment and not necessarily a valuable tool for increased social participation. At the same time, said games have been strongly opposed by educational organizations in Japan due to their potential negative effects on children. For instance, the National Congress of Parents and Teachers Association of Japan published "Appeal for the internet usage by young children" in 2014 to alert the public regarding the risks of digital devices such as smart phones, game consoles, or music players, which could lead to video game addiction or troubles on the Internet. Additionally, the Kagawa Prefectural Assembly has been drafting an ordinance to regulate the exposure of children under 18 years of age to TV, games, and the Internet in order to protect them from Internet addiction 
disorders or video game addiction. The enforcement of the "Law to Eliminate Discrimination against People with Disabilities (Shōgaisha sabetsu kaishō hou)" in 2016 could potentially enhance game accessibility for people with disabilities. This law is in line with the 2007 United Nations Convention on the Rights of Persons with Disabilities and was passed in 2013, three years before its enactment. It was in preparation until its actual enactment. Furthermore, it requires firms and local governments in Japan to provide reasonable accommodations that can be considered inclusive of "web accessibility", but it does not clearly define what "game accessibility" means.

Considering the current political situation wherein no remarkable initiatives to promote game accessibility by the national government in Japan have been made, more attention must be paid to for-profit corporations and the role they play in enhancing game accessibility for people with disabilities. How many major Japanese gaming corporations are providing games for people with physical disabilities? What kinds of concepts are used in developing such games? For further examination, the purpose of this paper is to analyze the current situation of game accessibility in Japan and identify the existing challenges in the development of games for people with physical disabilities. Possible methods to further enhance the development of games for people with disabilities are also discussed.

\section{Historical Background of Japan's Gaming Industry}

\subsection{Japan's Gaming Industry Dilemma: Competitive Content or Harmful Information?}

This section discusses the historical background of Japan's gaming industry, including the politics related to game accessibility. Japan's entertainment industry is often criticized for supposedly providing harmful information to the public. Likewise, other countries have made similar criticisms, and their respective governments have been constantly trying to regulate this allegedly harmful entertainment. Japan's Ministry of Education, Culture, Sports, Science and Technology (MEXT) and Japanese parent-teacher associations (PTAs) both have a relatively cautious approach to dealing with video games or online games because they are concerned about the possible harmful effects these might have on the Japanese youth. These harmful effects include the deterioration of visual acuity, obesity, poor academic performance, and the prevalence of extreme violence in games.

One of MEXT's primary objectives is to protect the Japanese youth and society from "harmful information." MEXT often refers to video games and online games as sources of "harmful information." For instance, in 2008, it established the "Roundtable on Children's Morals" to support the healthy growth of children to help them acquire "wholesome morals". The members of the roundtable are often vocal in their belief that information from television, games, mobile phones, and the Internet negatively affects Japanese children's mental growth and development. For instance, during the fourth roundtable meeting, the participating educators (e.g., elementary school and junior high school principals), educational nonprofit organization representatives, and university professors enumerated the following six problems: (1) children's exposure to harmful information; (2) the tendency of television to broadcast programs that spread misinformation and content that is either detrimental to education or done in bad taste; (3) the possibility that children can get addicted to the Internet and to using mobile (smart) phones; (4) the consequences on family life due to impaired real-world interpersonal relationships; (5) the dangers of anonymity in cyberspace; and (6) the inability of children to distinguish between the virtual world and the real world. (Interestingly, Japan's Computer Entertainment Supplier's Association (CESA) and Computer Entertainment Rating Organization (CERO) opted to protect the gaming industry through self-regulation-in alignment with the measures taken by the Entertainment Software Rating Board (ESRB) or Entertainment Software Association (ESA) in the U.S.-by collaborating with game or violence researchers and even with government officials for over two decades.)

To promote moral values, the roundtable proposed a "no-TV and no-game day" to be implemented in schools and localities to limit or minimize exposure to "harmful" media. In addition, more attractive 
activities such as face-to-face human interaction, reading picture books, singing lullabies with one's parents, and free play were identified as better alternatives to television, games, and browsing the Internet. However, a study by Nakamura, Matsuoka, and Inui found that time spent watching television and playing video games had an almost negligible negative causal relationship with time spent studying [3]. Nevertheless, such empirical studies are not often referenced in these roundtables.

On the other hand, economic reformists highly value the economic contributions of the gaming industry and support its further development on an international scale. This has been the view held by such reformers since they entered the political arena in the 2000s. The Ministry of Economy, Trade and Industry (METI), academia, and gaming companies all initiated this specific political trend. In 2006, METI, accompanied by the University of Tokyo and gaming companies such as Square Enix Holding Co., Ltd. (Tokyo, Japan), formed the "Game Industry Strategy Study Group" (Chairman: Akira Baba, University of Tokyo Professor) and published a report as the first step in formulating a national strategy for the future of the Japanese gaming industry. This was METI's first attempt at discussing the gaming industry in terms of an industrial strategy. In August 2006, the study group presented a report entitled "Strategy for Game Industry: Development and the Future Image of Game Industry." In this report, the gaming industry is identified as Japan's largest export industry in the area of domestic media content creation, and it is the largest contributor to the dissemination of Japanese culture and Japanese "branding" overseas [4].

Since the latter half of the 2000s, the content industry (i.e., industries responsible for the production and distribution of movies, animation, games, books, music, etc.) has been regarded as the main pillar of the "Cool Japan Strategy". The strategy aims to accomplish the following: (1) unearthing of domestic demand, (2) incorporation of foreign demand, and (3) transformation of the industrial structure. The accomplishment of these goals is projected to secure new income sources and jobs, leading to regional economic revitalization [5].

Nevertheless, these initiatives are essentially concerned with the exportation of the Japanese gaming industry to overseas markets and the establishment of a careful or cautious approach to domestic use. For instance, the section in the "Game Industry Strategy" report entitled "Communication Strategy: Strengthening Communication with Society" states the following: game companies have to (1) actively disseminate information to reduce concerns regarding games in society and among citizens; (2) provide a forum for dialogue with customers, parents, educational groups, media, etc., to establish interactive communication; and (3) deal with social issues such as education, learning, social welfare, and medical care by utilizing games. The report sends a strong message to society, asserting that the gaming industry does not impede education among youth, but instead, contributes to their well-being [4]. Game companies recognize that this criticism against the industry has increasingly been reinforced by the expansion of the mobile game market in recent years. Problems of excessive use (i.e., dependence or addiction) and in-game purchasing of high-cost items and subsequent billing are some reported problematic habits among the youth, who require supervision, guidance, or protection. Still, they insist that the industry should be seen as taking steps in being responsible as they prepare enlightenment booklets, dispatch experts to hold lectures about literacy, and advocate social initiatives such as barring illegal transactions of any kind [6].

\subsection{Politics Regarding Accessibility: Lower Priority of the Game Industry}

The double bind of the gaming industry is also reflected in the development of games for the disability community in Japan. Welfare policies for people with disabilities are implemented across Japanese agencies such as the Ministry of Health, Labour and Welfare (MHLW), the Ministry of Land, Infrastructure, Transport, and Tourism (MLIT), the Ministry of Internal Affairs and Communications (MIC or Soumusho), the MEXT, and the Cabinet Office. Among these, the MIC promotes policies on the accessibility of information for people with disabilities, as well as the elderly. The MIC has been developing an "information barrier-free" environment as one of the pillars of its information 
and communication technology policies (ICT policies), emphasizing the importance of the concept of accessibility as follows:

The advancement of ICT (Information and Communication Technology) brings significant reforms to society and brings various benefits to us. However, due to the digital divide due to age and physical conditions at present, it is also true that there are people who cannot enjoy these benefits, such as elderly people, people with disabilities, etc. The MIC has been making efforts to utilize ICT [to create] an environment that everyone, including the elderly and people with disabilities, can receive fruit with benefits. We are proactively promoting the following information barrier-related policies.

The focal points of its policies are (1) the promotion of a universal design, (2) support for individual needs, and (3) securing information literacy. Securing information accessibility is being promoted alongside universal design. The MIC has also been promoting telecommunications equipment accessibility, web accessibility, broadcasting services for visually handicapped people (i.e., improving broadcasting efforts of programs for the visually impaired through the preparation of subtitles/commentary broadcast penetration goals and the partial subsidization of subtitles/commentary programs' production costs), and accessibility to e-books.

However, considering that the term "game" does not appear in this policy, it can be inferred that the MIC does not strongly promote game accessibility for the elderly and people with disabilities compared to other platforms such as the web, e-books, etc. This political stance is also reflected in the budget allocation for people with disabilities.

Table 1 presents the outline of the budget (draft) for people with disabilities in the 2016 fiscal year. Accessibility to information is budgeted at approximately $¥ 570$ million (approximately $\$ 4.67$ million). This is in addition to living support, health and medical care, employment and support for economic independence, living environment, safety and security, resolution of discrimination, promotion of rights protection, and so on. The detailed breakdown of the $¥ 570$ million budget is shown in (1) to (4) of the same table: (1) Improvement of information accessibility in information communication includes the budget to implement electronic voting; (2) Enhancement of information provision, etc., includes budgets to achieve information accessibility equalization through broadcasting subsidy and commentary programs, subsidizing the production cost of sign language programs, etc. At the same time, subsidies for the promotion of barrier-free information in telecommunications and broadcasting have been provided to eliminate the digital divide caused by disability or age; (3) Enrichment of communication support includes the budgets for special equipment programs (Shōgaisha jiritsu shien kiki tou kaihatsu sokushin jigyō); (4) Barrier-free programs of administrative information include budgets to promote projects and surveys by public officials (e.g., municipalities) to improve the skills necessary to secure web accessibility. Based on the data in Table 1, accessibility to TV broadcasting, e-books, homepages, etc., has been consistently promoted by the Japanese national government. On the other hand, accessibility to games-which are considered a form of entertainment-has not been actively promoted. Games for people with disabilities are not regarded as part of the export content industry, and current domestic opposition toward the gaming industry only makes it more difficult for the government to support it. 
Table 1. Outline of the FY2016 budget for people with disabilities. Unit: ¥1 million.

\begin{tabular}{lc}
\hline & Financial Year 2016 \\
\hline 1. Living support & $1,207,684$ \\
2. Health and medical care & 376,866 \\
3. Education, culture and artistic activities, sports, etc. & 20,499 \\
4. Employment and support for economic independence & 204,347 \\
5. Living environment & 357 \\
6. Accessibility to information & 570 \\
(1) Improvement of information accessibility in information communication & $(8)$ \\
(2) Enhancement of information provision, etc. & $(447)$ \\
(3) Enrichment of communication support & $(158)$ \\
(4) Barrier-free program of administrative information & $(16)$ \\
7. Safety and security & 3047 \\
8. Resolution of discrimination, promotion of rights protection & 530 \\
9. Special consideration regarding administrative services & 519 \\
10. International relations & 8 \\
\hline
\end{tabular}

Source: Cabinet office [7]. Note: FY stands for "fiscal year".

\subsection{Development of Games for People with Disabilities by For-Profit Companies and CSR}

The background of the development of games for people with disabilities by for-profit companies is examined in this section. According to the definition by the European Commission, corporate social responsibility (CSR) refers to companies being accountable for their impact on society [8]. While the concept of CSR itself is not new, attention to CSR has gradually increased globally since the end of the 1990s. Compared to CSR in European countries, Japan's perception of CSR has been characterized by (1) compliance, (2) social contribution, and (3) efforts toward sustainability. This trend was especially prominent until the beginning of the 2000s [9]; it is said that 2003 was Japan's "First year of CSR (CSR gannen)".

CSR, compliance, and social contribution could further promote Japanese companies' efforts to address the concerns of people with disabilities. Although most companies tend to direct attention to their employment of people with disabilities, a wide range of efforts in aid of people with disabilities is also being executed [10]. A survey conducted by the Japan Business Federation (Keidanren) in 2009 found that many companies look to enhance social participation by working with people with disabilities as a part of their CSR. For instance, a bank in Kochi Prefecture installed new ATMs that were designed to accommodate the visually impaired. A medical company developed new radiographic X-ray equipment that significantly reduces the exposure time of the user to the equipment, thereby decreasing the stress experienced by patients with epilepsy, depression, bipolar disorder, and schizophrenia when using the equipment [11].

The concept of CSR has also encouraged companies and toy-related industrial groups to develop games for people with disabilities. The Japan Toy Association, a general industrial association, is a toy-related industry group founded in 1976 to achieve comprehensive development of the toy industry in Japan. It also promoted toy exports by collating the opinions of several toy industry circles regarding various issues, both domestic and international. It attempts to survey and oversee the production, distribution, export, and consumption of toys. The case of the Japan Toy Association (JTA) study mentions "toys" in general, which includes games, and how the JTA has been improving game accessibility. The aim of this initiative is to provide practical solutions to these issues through liaison with and coordination of each sector of the toy industry.

With respect to board members, a Tomy Company, Ltd. (Tokyo, Japan) representative sits as chairman and representatives from Bandai Co., Ltd. (Tokyo, Japan), Sega Toys Co., Ltd. (Tokyo, Japan), and Takara Tomy Arts Co., Ltd. (T-ARTS) (Tokyo, Japan) sit as executive directors. A Konami Digital Entertainment Co., Ltd. (Tokyo, Japan) representative is the director (as of June 29, 2016). 
The association's main functions are as follows: (1) to host the International Tokyo Toy Show, (2) to implement Toy Safety Business (ST Mark certification), and (3) to design accessible design toys (universal-use toys). "Accessible design toys" (Kyōyū gangu) are toys which are specially designed so that children with visual or auditory disabilities can also enjoy them. In order to develop and sell such toys, cooperation with various welfare groups such as the Japan Braille Library is key [12]. (However, according to the "Toy Catalog for Accessible Design Toys, 2016", TV games and online games are not considered as accessible design toys despite the availability of games supplied through iPads.) The development of such toys only accounts for a small percentage of for-profit companies' sales, but the association regards these projects as social contribution activities by game-related industrial organizations in general [13]. The next section discusses the research questions and methodology.

\section{Research Questions and Methodology}

\subsection{How Can "Games for People with Disabilities" Be Defined?}

The Accessible Design Foundation of Japan (ADF Japan) defines "accessible products and services" (Kyoyohin products and services) as things "designed to be used by as many people as possible, including older persons and persons with disabilities". These products and services are characterized by the following principles: (1) they meet various physical and intellectual needs; (2) they are easily communicable using multiple means (e.g., visual, auditory, and tactile aids); (3) they are operational methods that can be intuitively understood and cause little psychological strain; (4) they are easy to use with little physical burden (i.e., they can be handled with minimum effort and easily accommodate motion, approach, etc.); and (5) all of their components are considered safe, including materials, structure, function, procedure, and sustainability-friendly features [14].

Figure 1 illustrates the basic concept of accessible products and services. These include mainstream assistive technology (II), Kyoyohin goods (III), and barrier-reducing goods (IV).

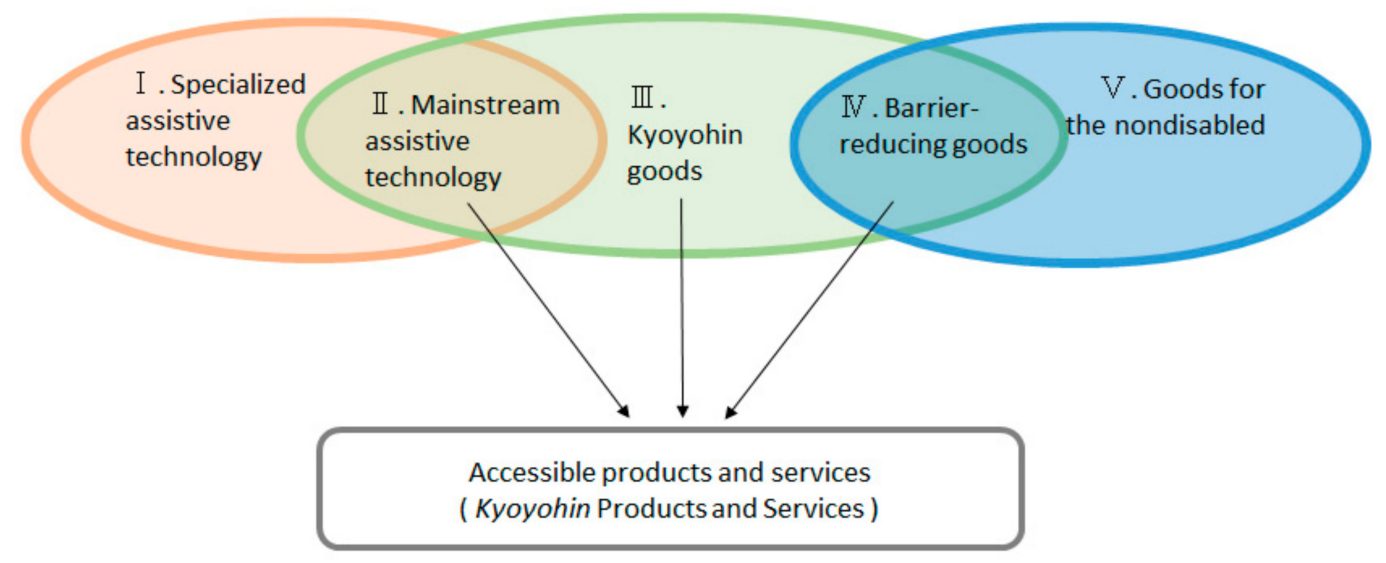

Figure 1. Concept of Kyoyohin products and services (Source: Accessible Design Foundation of Japan (ADF Japan) [14]; What is Accessible Design?).

The above concept provides the basis for the definition of the term "games for people with disabilities." The term includes the following four categories: specialized assistive games for people with disabilities (I); mainstream assistive games (II); Kyoyohin games (III); and barrier-reducing games (IV).

\subsection{Research Questions}

The survey conducted on the major Japanese gaming corporations and toy corporations contained the following questions. While it was possible to directly analyze the titles published by the companies involved, extra measures were taken to obtain comprehensive data through a survey instead. 
RQ1: How many major Japanese gaming corporations are providing games for people with physical disabilities?

RQ2: What kinds of concepts are being used when developing games for people with physical disabilities?

RQ3: How do the major Japanese gaming corporations communicate with the disability community when developing games for people with physical disabilities?

Tables 2 and 3 contain the research sample and the content of the survey. The survey was emailed to the major Japanese gaming corporations from June 2017 to July 2017 and sought to determine whether they have had any prior experience in developing and/or supplying games for people with disabilities. The following two criteria were used in selecting the companies for the survey: (1) The top 10 corporations for the 2016 fiscal year in the "industry trend search" (http://gyokai-search.com/)—a tool that discloses the annual sales of each corporation given their annual securities report-were selected based on their sales performance in the industry categories of "gaming industry" and "toy industry." Needless to say, there were other smaller Japanese gaming corporations and toy corporations, but in this paper we only focused on the major gaming corporations and examined their influence among not only the domestic gaming communities, but also the disability community. Six companies, namely, Sony Corporation (Tokyo, Japan), Nintendo Co., Ltd. (Kyoto, Japan), Bandai Namco Entertainment, Inc. (Tokyo, Japan), Sega Sammy Holdings Inc. (Tokyo, Japan), Konami Holdings Corporation (Tokyo, Japan), and Square Enix Holdings Co., Ltd. (Tokyo, Japan), were in both categories, resulting in 14 firms being selected as the sample of corporations through this criterion. (2) Corporations that have been published in newspaper articles and/or publications, etc., or have a track record for creating games for people with disabilities were also considered. Based on this criterion, Taito Corporation (Tokyo, Japan) was subsequently added to the sample list.

Table 2. Target of the survey.

1. Bandai Namco Entertainment
2. Capcom Co., Ltd.
3. Colopl, Inc.
4. DeNA Co., Ltd.
5. GungHo Online Entertainment, Inc.
6. Happinet Corporation
7. Konami Holdings Corporation
* The response was from Konami Amusement.
8. NEXON Co., Ltd.
9. Nintendo Co., Ltd.
10. Pigeon Corporation
11. Sega Sammy Holdings
* The response was from Sega Holdings.
12. Sony
* The response was from "Sony Interactive Entertainment"
13. Square Enix Co., Ltd.
14. Taito Corporation
15. Tomy Company, Ltd.

Table 3. Content of the survey.

Content of Survey

(1) Are your games designed for ease of use with current or past consoles, game software, and for people with disabilities?

(2) If any game machines and game software have been developed with the disability community in mind, please name the product.

The survey sent to Konami Holdings Corporation was answered by Konami Amusement Co., Ltd., a subsidiary company that handles its amusement businesses. Similarly, the surveys sent to Sega 
Sammy Holdings Inc. and Sony Corporation were answered by Sega Holdings Co., Ltd. (Tokyo, Japan) and Sony Interactive Entertainment Inc., respectively.

A total of 15 corporations (indicated in Table 2) were selected for this study. Among them, 13 responded to the survey, yielding a response rate of $86.6 \%$. However, 4 companies out of these 13 respondents indicated that they could not respond to this type of survey, while 2 said that they did not develop video games themselves. Therefore, the responses of 7 out of the 15 companies were used.

Social networks were also analyzed to identify the prominent actors who are active in the socially networked game community for people with disabilities. They were asked the following question:

RQ4: Who is advocating game accessibility in Japan online?

Based on Borgatti's Network Analysis [15], the following indicators were used: (1) closeness centrality and (2) the clustering coefficient. These indicators can be used to measure the level and type of involvement among the actors in a network. Closeness centrality provides a measurement to determine the patterns of how actors make ties. Borgatti used these centrality measures to observe the ties among advocacy networks. According to him, the closeness centrality can be used to measure the degree of an actor's direct communication with other actors [15]. Visualizing advocacy networks allows one to better understand the features and other patterns among different organizations that are involved in games for people with disabilities.

Node XL facilitates analysis of these network indicators and helps in the identification of subgroups in advocacy networks [16]. Deeper analysis of the cluster can help identify subgroups and can therefore reveal the networking of subgroups, as well as the ways that advocacy is being led in these networks [17]. The results illustrate how advocacy activities are supported by actors in a network, allowing the researcher to focus on who is leading each subgroup. The subsequent results then provide an insight into the patterns of advocacy activities that are controlled by the leading actor in a subgroup through the centrality indices.

The centrality measures were calculated and the networks for video game development for people with disabilities were drawn using YouTube video data. The data were chosen according to following criteria: the videos' titles, keywords, descriptions, categories, or author's usernames had to contain specific keywords associated with people with disabilities such as "easy mode" (rakuraku mōdo) and "color vision support function" (shikikaku sapōto kinou). Correspondingly, the network was drawn in the following manner: The size of the vertices was proportional to the square root of the closeness centrality. Each edge was weighted by the number of linking actors/organizations and added for each pair of videos with the same category. The vertices were positioned in accordance with the Fruchterman-Reingold algorithm.

\section{Results and Discussion}

\subsection{Current Situation of Video Games for People with Disabilities in Japan}

How many major Japanese gaming corporations are providing games for people with disabilities (RQ1)? Table 4 indicates the answers from each company. Five companies (38.5\%) - Sony Corporation, Konami Amusement Co., Tomy Company, Ltd., GungHo Online Entertainment, Inc. (Tokyo, Japan), and Taito Corporation - expressed that they have developed either (1) games for people with disabilities or (2) games that are accessible to all users and consumers, including senior citizens and people with disabilities. 
Table 4. List of games for people with disabilities by each company (Japan survey results).

\begin{tabular}{|c|c|}
\hline $\begin{array}{l}\text { GungHo } \\
\text { Online } \\
\text { Entertainment, } \\
\text { Inc. }\end{array}$ & $\begin{array}{l}\text { We implemented a "color vision support function" for the game "Puzzle \& Dragons" in } 2014 . \\
\text { "Color vision support function" is a support function for those who experience difficulty } \\
\text { identifying colors in some specific color combinations. When this option is turned ON, the color of } \\
\text { the "drop" in the game is changed to support color identification. }\end{array}$ \\
\hline $\begin{array}{c}\text { Konami } \\
\text { Amusement }\end{array}$ & $\begin{array}{l}\text { In our games that use coins or medals for amusement arcade facilities, we designed them so that } \\
\text { one can switch to a mode that makes it easier for the elderly to operate, in addition to our normal } \\
\text { mode. For instance, "G I-HORSEPARK JUDGMENT", which is a horse racing medal game, has an } \\
\text { "easy mode (rakuraku mōdo)" embedded within. This mode can switch the interface to make it } \\
\text { easier for the elderly and beginners to start playing the game. By switching to "Easy mode," the } \\
\text { UI (User Interface) design makes it possible to display information with larger text and change the } \\
\text { layout to improve the overall experience. During the development stage, we implemented an } \\
\text { experiment called "meeting by senior citizens" wherein we let them play and produced games } \\
\text { according to their feedback. Additionally, in regards to other coin and medal games, switching to } \\
\text { the "easy mode" has made it possible to narrow down the variety of the games and therefore } \\
\text { simplify the experience for beginners and others. }\end{array}$ \\
\hline $\begin{array}{l}\text { Sega Sammy } \\
\text { Holdings }\end{array}$ & $\begin{array}{l}\text { We have been devoting efforts towards implementing improvements so that everyone, regardless } \\
\text { of age and gender, can enjoy our products. However, we have never developed products solely } \\
\text { focusing specifically on people with disabilities and/or the elderly. }\end{array}$ \\
\hline $\begin{array}{c}\text { Sony } \\
\text { Interactive } \\
\text { Entertainment } \\
\text { Soln }\end{array}$ & $\begin{array}{l}\text { Sony Interactive Entertainment has been developing games so that all people, with or without } \\
\text { disabilities, can have better access to our games with ease in mind. } \\
\text { Regarding hardware: } \\
\text { We are currently developing and selling consoles or gaming hardware called PlayStation } 4 \text { (PS 4) } \\
\text { and PlayStation Vita (PS Vita). PS } 4 \text { is a stationary-type console or game machine that began } \\
\text { selling in Japan in February 2014. PS Vita is a portable game machine that we introduced to the } \\
\text { Japanese market in December 2011. Both PS } 4 \text { and PS Vita have their own system software, and by } \\
\text { upgrading this system software, we have made it possible to add functions, improve operability, } \\
\text { and enhance security. Functions related to accessibility are also improved by upgrading the } \\
\text { version of this software. PS } 4 \text { and PS Vita can alter the setting of "accessibility". In "accessibility", } \\
\text { it is possible to customize screens to the related settings integrated with the system settings to } \\
\text { make it easier to use. For example, one can alter screen zoom, color reversal, large letters, bold } \\
\text { letters, high contrast, and closed caption, change button assignment, change automatic scroll } \\
\text { speed (PS } 4 \text { only), etc. In addition to that, with PS4, you can enjoy communication between users } \\
\text { by sending and receiving stamps, as well as characters, using the "message" function. } \\
\text { Furthermore, a "text-to-speech" function (that only corresponds to some regions and languages) } \\
\text { that reads the text displayed on the screen or browser is also included. } \\
\text { Regarding software: } \\
\text { We have a production department called SIE Worldwide Studio, which produces game software } \\
\text { for the PlayStation Platform. The game for PS } 4 \text { titled "Uncharted: Pirate King and Last Hidden } \\
\text { Treasure," which was developed by NAUGHTY DOG, which is one of our studios in the United } \\
\text { States, has installed accessibility functions based on advice from people with disabilities. In this } \\
\text { game, you need various controls by using the controller buttons and stick with both hands. For } \\
\text { instance, there are some scenes where characters move hard or shoot guns. In that case, by using } \\
\text { the accessibility setting, you can do the same operation with only one hand or button long press. }\end{array}$ \\
\hline $\begin{array}{c}\text { Taito } \\
\text { Corporation }\end{array}$ & $\begin{array}{l}\text { "Games for the visually disabled-Space Invaders for the Visually Disabled" was sold in Japan, } \\
\text { July } 2003 . \\
\text { Background of development: } \\
\text { We have consulted the Japan Software Company for the Handicapped and released games as a } \\
\text { form of collaboration, so the concept is not solely a product of in-house development. We have not } \\
\text { developed other games for people with disabilities. }\end{array}$ \\
\hline $\begin{array}{l}\text { Tomy } \\
\text { Company, } \\
\text { Ltd }\end{array}$ & $\begin{array}{l}\text { Shogakukan's picture book NEO Pad was introduced to the Japanese market on July } 15,2017 . \\
\text { Because our main products are toys, there are no game machines or game software that uses the } \\
\text { TV screen. However, we offer tablet machine games for children with hearing disabilities. They } \\
\text { were developed so that they can easily play with them. It is possible to determine the sound } \\
\text { volume with your own eyes (you can also put it into silent mode). When taking pictures at the } \\
\text { camera segment, we made alterations so that you can see the signs that you took even with your } \\
\text { eyes, according to the shutter sound of the camera. We implemented expression-sensitive game } \\
\text { development from the initial stage until the end (you can enjoy the progression of the game even } \\
\text { solely with text characters and icon displays without relying on sound). We had advanced } \\
\text { monitor use with experts of hearing disorders, parties, and children with hearing disabilities, } \\
\text { during the development of this product. }\end{array}$ \\
\hline
\end{tabular}




\subsection{Concepts Associated with Providing Games for People with Disabilities}

What kinds of concepts are used when developing games for people with physical disabilities (RQ2)? As mentioned earlier, this concept was utilized to define the term "games for people with disabilities". This term includes the following four categories: specialized assistive games for people with disabilities (I); mainstream assistive games (II); Kyoyohin games (III); and barrier-reducing games (IV). The survey responses indicated that only one out of the five companies that responded developed video games with specialized assistive technology (I). Specifically, Taito Corporation provided their "Games for the visually impaired-Space Invaders for the Visually Impaired" (which was sold in Japan in July 2003).

The remaining four companies can be categorized as having developed games for people with disabilities based on the concept of barrier-reducing goods (IV). For instance, Sony Interactive Entertainment Inc. stated that "Sony Interactive Entertainment has been developing games so that all people, with or without disabilities, can have better access to our games with ease in mind". Sega Sammy Holdings Inc. also said that "We have been devoting efforts towards implementing improvements so that everyone, regardless of age and gender, can enjoy our products". The former emphasized their active development of games with higher accessibility so that every user can easily use their products. However, the latter mentioned that although they have never developed games solely for senior citizens or people with disabilities, they have developed games so that every user-including senior citizens or people with disabilities—can enjoy them.

\subsection{Communication with Disability Communities}

How have the major Japanese gaming corporations communicated with the disability communities (RQ3)? Three out of five companies (23.1\%) stated that they have previously communicated with disability communities to develop games for people with disabilities. Konami Amusement Co., Ltd. specifically said that "During the development stage, we implemented an experiment called "meeting by senior citizens" wherein we let them play and produced games according to their feedback". Additionally, Tomy Company Ltd. responded that "We had advanced monitor use with experts of hearing disorders, parties, and children with hearing disabilities during the development of this product". Taito Corporation also answered that "We have consulted the Japan Software Company for the Handicapped and released games as a form of collaboration".

\subsection{Challenges for Providing Games for People with Disabilities}

What are the challenges encountered when providing games for people with disabilities in Japan? First, responses to RQ1 indicate that the major Japanese gaming-related companies have indeed developed games for people with disabilities in the past, regardless of their low profitability. Five out of 13 companies (38.5\%) stated that they have developed either games for people with disabilities or games that are accessible to all users and consumers, including senior citizens and people with disabilities.

Second, responses to RQ2 also indicate that major Japanese gaming corporations develop games for people with physical disabilities based on the concept of barrier-reducing games (IV). All companies which provide games for people with disabilities responded that they do so for people with hearing and/or visual impairments, but none of the corporations replied that they had provided games for people with physical disabilities. In other words, games for those who need specialized assistive technology and/or mainstream assistive technology were not taken into account.

Third, responses to RQ3 indicate that the major Japanese gaming corporations do not tend to actively communicate with disability communities. Three out of five companies (23.1\%) stated that they communicated with disability communities to develop games for people with disabilities. If the disability communities were given more opportunities to participate during the development phase, more games with the necessary considerations could be developed and released. 


\subsection{Network Analysis}

In this section, the Japanese political and economic situation regarding games for people with disabilities was analyzed through the responses to RQ4 (Who is advocating game accessibility in Japan online?). In summary, the gaming industry is likely to be considered as a harmful form of entertainment from an educational standpoint; hence, it may be difficult to gain considerable support from the national government. Under such circumstances, game-related for-profit companies and industrial organizations have developed games with accessibility as part of their CSR. This was confirmed using social network analysis.

\subsection{Result of the Network Analysis: Higher Presence of Gaming Companies}

Figure 2 illustrates the network of actors who interacted with the YouTube video about "easy mode" (rakuraku mōdo) which was developed by Konami Holdings Corporation (Konami) (Tokyo, Japan). The encircled black circle within the network links represents Konami's official account, whereas the other small dots around it primarily represent the users of the games. In the e-mail survey, Konami stated that they developed the "easy mode" with senior citizens and gained valuable feedback on how senior citizens and beginners can easily become familiar with the games. This figure indicates that Konami has productive networks which are essential to the development of games for people with disabilities.

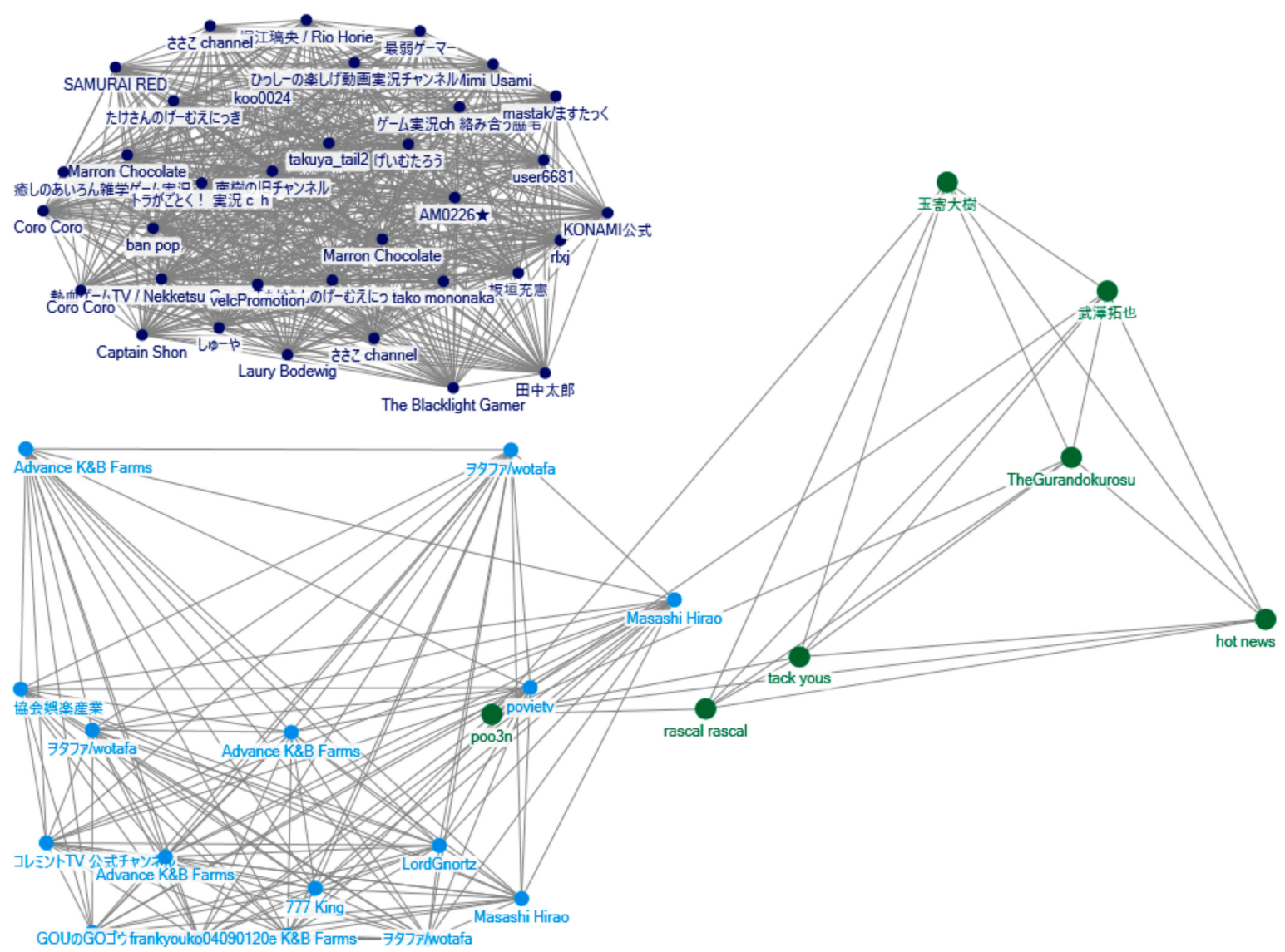

Figure 2. Node XL network regarding easy mode (rakuraku mōdo).

Figure 3 illustrates the network of actors who interacted with the YouTube video about the "accessibility" of the "PlayStation", which was developed by Sony Corporation (Sony). The encircled black circle within the network links represents PlayStation Japan, whereas the other small dots around it represent the users of the games. In the e-mail survey, Sony responded as follows: 
We have developed "user friendly" games not only for people with disabilities, but for all of our users; and in terms of "game accessibility", functions have gradually been improved and upgraded. For instance, PlayStation ${ }^{\circledR} 4$ and PlayStation ${ }^{\circledR}$ Vita have screen settings of accessibility such as the option to invert colors, make the font size larger or smaller, bold letters, or high contrast, change button assignments, etc.

This figure indicates that Sony also has productive networks which are essential to the development of games for people with disabilities.

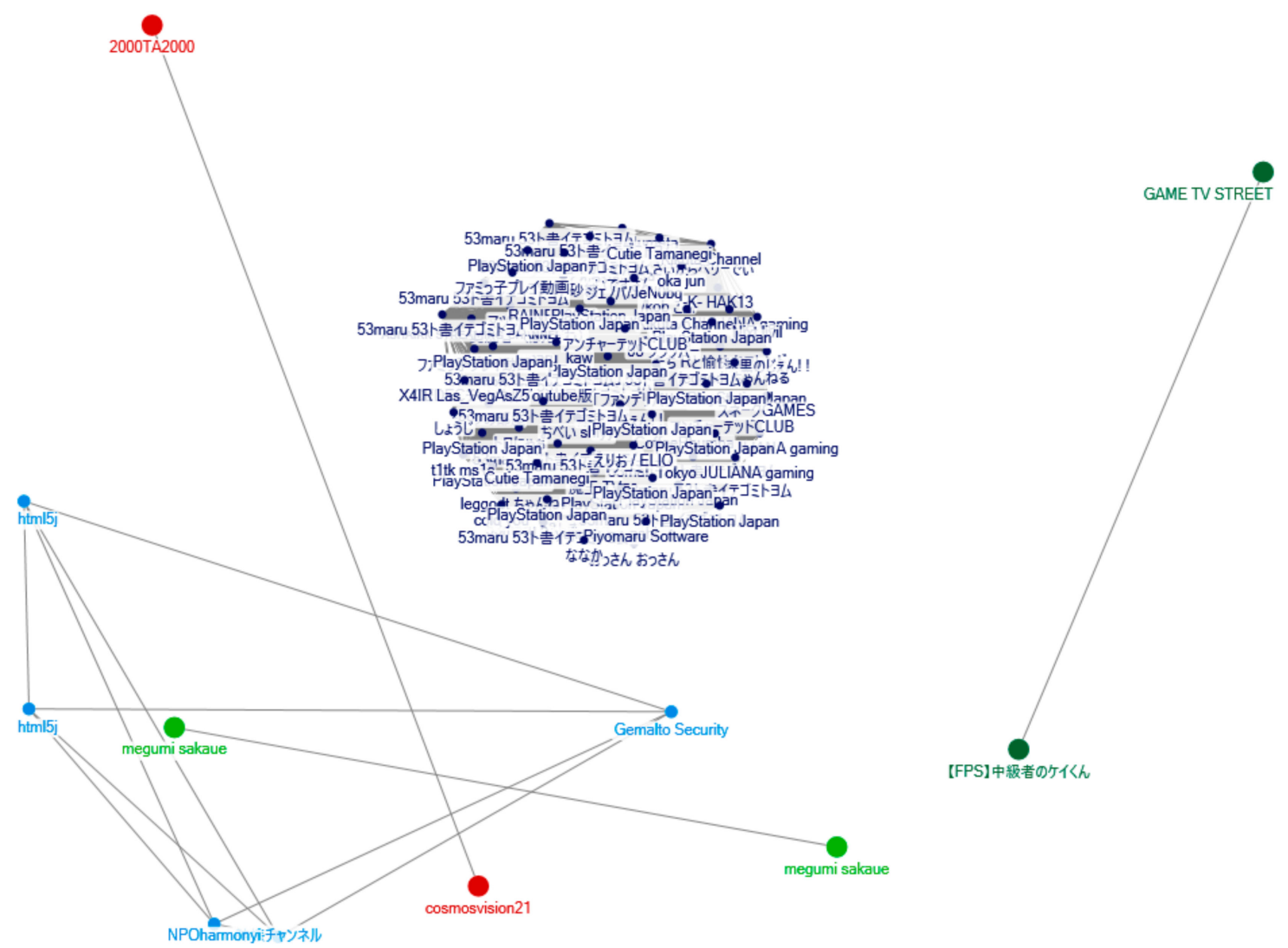

Figure 3. Node XL network regarding the accessibility of the PlayStation ${ }^{\circledR}$.

Figure 4 illustrates the network of actors who interacted with the YouTube video about the "color vision support function" (shikikaku sapōto kinou), which is software developed by GungHo Online Entertainment, Inc. (Gungho). The encircled black circle within the network link represents an ophthalmological clinic in Aichi Prefecture, whereas the other small dots around it represent the users of the games. This figure indicates that the function developed by GungHo gained the attention of the game users as well as welfare groups. However, the presence of the Japanese national government within the network cannot be confirmed.

These figures illustrate that the gaming companies and users, including welfare organizations, have some interest in (and focus their attention on) games for people with disabilities, while the national government has shown little interest toward such games. 


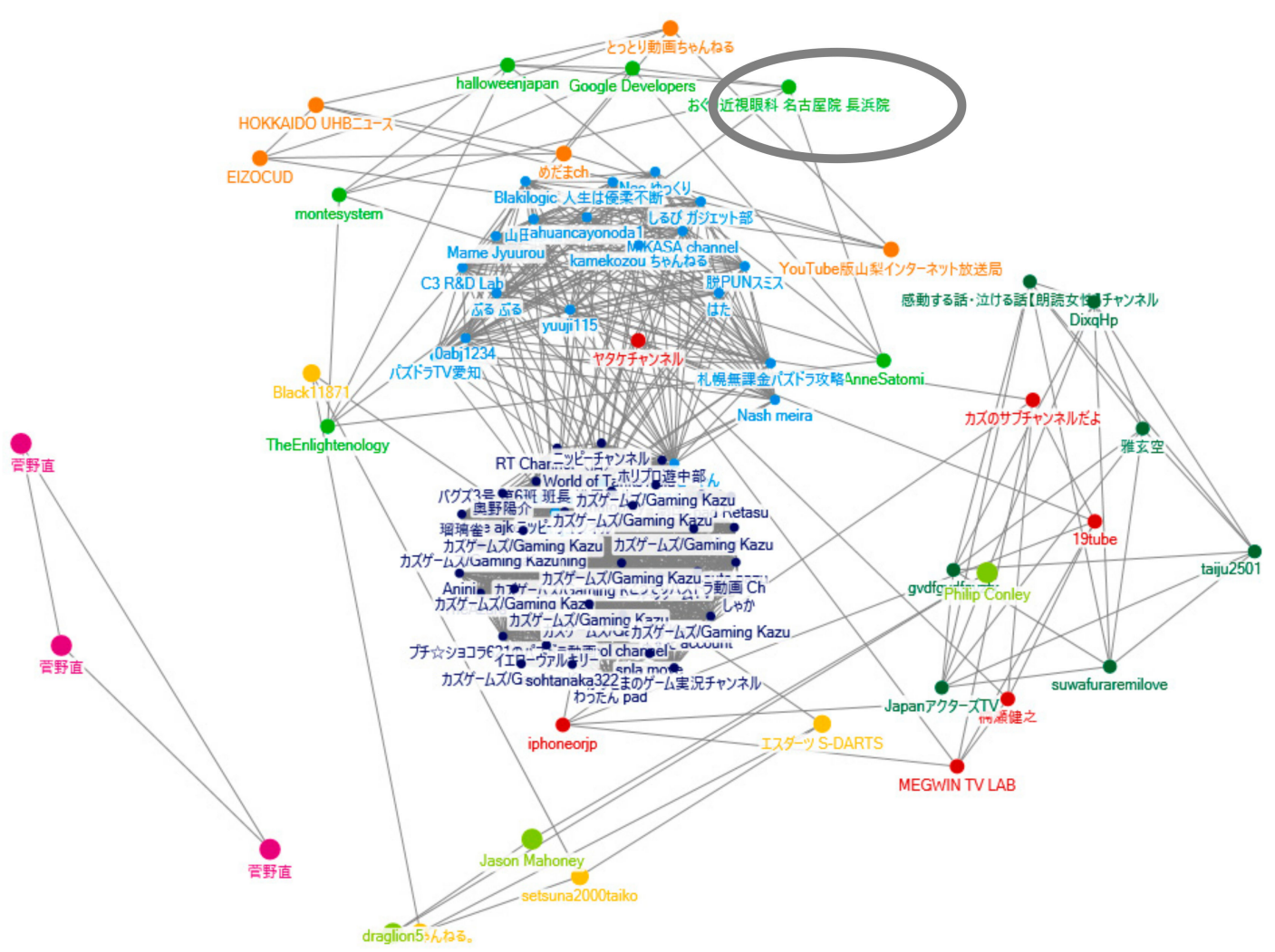

Figure 4. Node XL network regarding the "color vision support function" (shikikaku sapōto kinou).

\section{Conclusions}

Video and online games have been among Japan's major entertainment industrial exports and are globally renowned Japanese cultural industries. In the past, Nintendo gaming consoles were found in almost every household, not only in Japan but in many other countries as well. Sega and Playstation, along with other platforms, compete for the attention of the youth around the world. Sony, Nintendo, and Bandai Namco were initially established as Japanese companies in other fields but are now primarily associated with games, becoming the leading developers of video games and online games over the past few decades. Although foreign competitors have emerged, Japanese companies maintain their competitive advantage in the global video game industry and market.

Games and web services for the disability community also have been developed in Japan, and some efforts to achieve broader "game accessibility" have been implemented, despite the latter's diffusion not being as rapid as anticipated. The significance of "game accessibility" has slowly but constantly been gaining prominence in Japan, although the gaming industry is still struggling to understand how to properly accommodate the disability community. At the same time, however, there is a relatively limited understanding of the extent of for-profit corporations' roles in enhancing game accessibility for people with disabilities. Therefore, this survey was conducted on the major gaming companies to carefully examine the environment.

The survey results determined that approximately $40 \%$ of gaming companies are developing games for people with disabilities. Furthermore, most of them have actually made attempts to give consideration to people with disabilities by developing special functions such as "easy mode" and "support for visual disabilities". Specifically, a company provided information on how they developed games based on the concept of specialized assistive technology, and four companies mentioned how they developed games for people with disabilities based on the concept of barrier-reducing goods. However, this survey also revealed that major Japanese gaming corporations had a tendency of not actively communicating with disability communities. The results indicate that creating stronger 
interactions with the gaming companies could directly promote further development of games for people with disabilities. In addition, given that video and online games are significant means of social participation for people with disabilities, more social understanding is needed in the Japanese domestic context.

This study is significant in the sense that it has been able to give insight into the mindset of Japanese gaming corporations, their perception of the disability community, and their commitment to enhancing the latter's inclusion into society. As a by-product, the survey may have also prompted the Japanese corporations to review their policies toward the disability community and possibly create some movement toward the creation of more games for people with disabilities. As the survey is limited to Japan, further research is needed to make conclusions about the gaming industry, as well as relevant regulations or policies, in other countries. However, because Japan is a major force in the creation of games and equipment, the survey can be considered as an important first step in investigating how gaming corporations view the disability community.

The limitations of this paper are as follows: The data used for the study were from 2016 and 2017, and the survey is a few years old, so this paper may only be seen as a snapshot of Japan from 2016 to 2017. Needless to say, this paper did not cover recent developments despite the numerous advancements and changes related to video games accessibility that have occurred in recent years. Also, the disability community was not contacted in order to get information on game accessibility. The researchers hope that said problems are dealt with in the future.

Author Contributions: M.K. and S.O. equally contributed to the creation of this paper. All authors have read and agreed to the published version of the manuscript.

Funding: This study was generously supported by JSPS KAKENHI Grant Number 17K13668.

Acknowledgments: The authors would like to thank the three anonymous reviewers for their comments. The authors would also like to thank the editors and staff for their support during the publication process.

Conflicts of Interest: The authors declare no conflict of interest.

\section{References}

1. Powers, G.M.; Nguyen, V.; Frieden, L.M. Video Game Accessibility: A Legal Approach. Disabil. Stud. Q. 2015, 35. [CrossRef]

2. Yuan, B.; Folmer, E.; Frederick, C.H., Jr. Game accessibility: A survey. Univers. Access Inf. Soc. 2011, 10, 81-100. [CrossRef]

3. Nakamura, M.; Matsuoka, R.; Inui, T. More Time Spent on Television and Video Games, Less Time Spent Studying? RIETI Discussion Paper Series 13-E-095; 2016, pp. 1-29. Available online: http://www.rieti.go.jp/ jp/publications/dp/13e095.pdf (accessed on 19 July 2017).

4. The University of Tokyo. Gēmu Sangyō senryaku Gēmu Sangyō no Hatten to Mirai zou Kisha Setsumeikai no Goannai [Information of the Press Conference: Strategy for Game Industry: Development and Future Image of Game Industry]. 2006. Available online: http://www.u-tokyo.ac.jp/content/400008405.pdf (accessed on 28 July 2017).

5. METI (Ministry of Economy, Trade, and Industry). Cool Japan Strategy. 2012. Available online: http: //www.meti.go.jp/english/policy/mono_info_service/creative_industries/pdf/120116_01a.pdf (accessed on 28 July 2017).

6. Institute for Information and Communication Policy. Research Report on International Development and Prospect of ICT Emerging Field. 2014. Available online: https://www.soumu.go.jp/iicp/chousakenkyu/data/ research/survey/telecom/2014/2014game.pdf (accessed on 28 July 2017).

7. Cabinet Office (Japan). Heisei 28 nendo shōgaisha shisaku kankei yosan (an) no gaiyou [The Outline of the Budget (draft) for People with Disabilities in FY2016]. 2015. Available online: http://www8.cao.go.jp/ shougai/suishin/yosan/pdf/yosan.pdf (accessed on 28 July 2017).

8. European Commission. Corporate Social Responsibility (CSR). 2017. Available online: http://ec.europa.eu/ growth/industry/corporate-social-responsibility_en (accessed on 28 July 2017). 
9. Tanimoto, K. Nihon Kigyō no CSR keiei [CSR Management in Japanese Corporations]; Chikura Publishing: Tokyo, Japan, 2014.

10. Kuroda, K.; Hasegawa, M. Kigyō no shakai teki sekinin (CSR) to shōgaisha shien: Suuji kara miru kigyō no shōgaisha koyou shien no jittai [Corporate social responsibitily (CSR) and social support for people with disabilities: Evidence from employment of people with disabilities by for-profit companies]. Nōmaraizēshon [Normalization] 2010, 30, 10-12.

11. Japan Business Federation. Jirei chōsa hen [Case studies]. CSR (Kigyō no shakai tekisekinin) ni kansuru kankēto chōsa kekka [A results of questionnaire surveys regarding CSR (Corporate Social Responsibility)]; Japan Business Federation: Tokyo, Japan, 2009.

12. JTA (Japan Toy Association). Japan Toy Association Business Information. 2016. Available online: http://www.toys.or.jp/pdf/jta_business_info_english.pdf (accessed on 28 July 2017).

13. JTA (Japan Toy Association). Kyōyū gangu suishin bukai no katsudou [Activities by division of Accessible design toys (Kyōyū gangu)]. 2017. Available online: http://toys.or.jp/jigyou_kyoyuu_katsudo.html (accessed on 28 July 2017).

14. ADF Japan (The Accessible Design Foundation of Japan). The Accessible Design Foundation of Japan. 2017. Available online: http://www.kyoyohin.org/en/kyoyohin/pdf/About_ADF.pdf (accessed on 28 July 2017).

15. Borgatti, S. Centrality and network flow. Soc. Netw. 2005, 27, 55-71. [CrossRef]

16. Smith, M.A.; Shneiderman, B.; Milic-Frayling, N.; Rodrigues, E.M.; Barash, V.; Dunne, C.; Capone, T.; Perer, A.; Gleave, E. Analyzing (social media) networks with NodeXL. In Proceedings of the Fourth International Conference on Communities and Technologies, University Park, PA, USA, 25-27 June 2009; Carroll, J.M., Ed.; ACM: New York, NY, USA, 2009; pp. 255-264. [CrossRef]

17. Hansen, D.; Shneiderman, B.; Smith, A.M. Analyzing Social Media Networks with NodeXL: Insights from a Connected World; Morgan Kaufmann Publishers: Burlington, VT, USA, 2011.

(C) 2020 by the authors. Licensee MDPI, Basel, Switzerland. This article is an open access article distributed under the terms and conditions of the Creative Commons Attribution (CC BY) license (http://creativecommons.org/licenses/by/4.0/). 